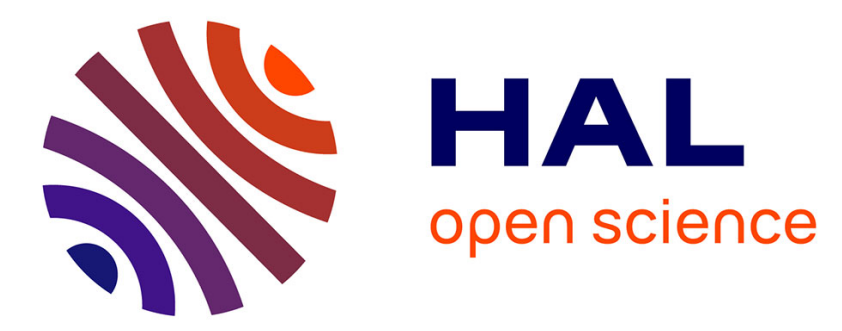

\title{
Influence of precipitate/supernatant ratio during liquid-phase synthesis of solid electrolyte Li7P3S11
}

Bo Fan, Quanfeng Zhang, Zhongkuan Luo, Xianghua Zhang, Hongli Ma, Ping Fan, Bai Xue

\section{- To cite this version:}

Bo Fan, Quanfeng Zhang, Zhongkuan Luo, Xianghua Zhang, Hongli Ma, et al.. Influence of precipitate/supernatant ratio during liquid-phase synthesis of solid electrolyte Li7P3S11. Solid State Ionics, 2019, 343, pp.115073. 10.1016/j.ssi.2019.115073 . hal-02367902

HAL Id: hal-02367902

https://hal-univ-rennes1.archives-ouvertes.fr/hal-02367902

Submitted on 30 Mar 2020

HAL is a multi-disciplinary open access archive for the deposit and dissemination of scientific research documents, whether they are published or not. The documents may come from teaching and research institutions in France or abroad, or from public or private research centers.
L'archive ouverte pluridisciplinaire HAL, est destinée au dépôt et à la diffusion de documents scientifiques de niveau recherche, publiés ou non, émanant des établissements d'enseignement et de recherche français ou étrangers, des laboratoires publics ou privés. 


\title{
Influence of precipitate/supernatant ratio during liquid-phase synthesis
}

\author{
of solid electrolyte $\mathrm{Li}_{7} \mathrm{P}_{3} \mathrm{~S}_{11}$
}

\author{
Bo Fan ${ }^{\mathrm{a}}$, Quanfeng Zhang ${ }^{\mathrm{a}}$, Zhongkuan Luo ${ }^{\mathrm{b}}$, Xianghua Zhang ${ }^{\mathrm{c}}$, Hongli Ma ${ }^{\mathrm{c}}$, Ping \\ Fan $^{\mathrm{a}}$, Bai Xue $\mathrm{a}^{\mathrm{a}}$
}

aShenzhen Key Laboratory of Advanced Thin Films and Applications, College of Physics and Optoelectronic Engineering, Shenzhen University, Shenzhen, 518060, China

b Shenzhen Key Laboratory of New Lithium-ion Battery and Mesoporous Materials, College of Chemistry and Environmental Engineering, Shenzhen University, Shenzhen, 518060, China

${ }^{\mathrm{c} U n i v}$ Rennes, CNRS, ISCR (Institut des Sciences Chimiques de Rennes) - UMR 6226, Rennes 35042, France

\section{Abstract}

Delicate control of the precipitate/supernatant ratio in the precursor suspension during liquid-phase synthesis of $\mathrm{Li}_{7} \mathrm{P}_{3} \mathrm{~S}_{11}$ provides information on how the morphology of the impurities affect the ionic conductivity. In this work, the influence of the precipitate/supernatant ratio on the phase structure, the morphology and the ionic conductivity of $\mathrm{Li}_{7} \mathrm{P}_{3} \mathrm{~S}_{11}$ prepared in acetonitrile is studied. It is revealed that in the supernatant-excess region, the excess amorphous " $\mathrm{Li}_{2} \mathrm{~S} \cdot \mathrm{P}_{2} \mathrm{~S}_{5}$ " finally turns into a poorly ionic conductive phase $\mathrm{Li}_{4} \mathrm{P}_{2} \mathrm{~S}_{6}$ which wraps $\mathrm{Li}_{7} \mathrm{P}_{3} \mathrm{~S}_{11}$ particles, increasing the interfacial resistance. In the precipitate-excess region, a thio-LISICON III phase turned from the excess precipitate tends to stay within $\mathrm{Li}_{7} \mathrm{P}_{3} \mathrm{~S}_{11}$ particles, and therefore its negative influence on the total ionic conductivity is not evident. Consequently, a slight composition shift into the precipitate-excess region benefits the ionic conductivity of the resultant solid electrolyte.

Keywords: solid electrolyte; liquid phase synthesis; lithium thiophosphate; ionic conductivity

\footnotetext{
* Corresponding author.Tel: +86 (0)755 26534995
}

E-mail address:baixue@szu.edu.cn 


\section{Introduction}

Sulfide solid electrolytes (SEs) are promising ion transport materials for solid-state $\mathrm{Li} / \mathrm{Li}$-ion batteries because of their excellent lithium-ion conductivity. Among the studied SEs (including oxide SEs and polymer SEs), sulfide SEs are the only category which has been found to achieve room-temperature lithium-ion conductivity comparable with that of the liquid electrolytes. ${ }^{1,2}$ These super ionic conductive sulfide SEs include $\quad \mathrm{Li}_{10} \mathrm{GeP}_{2} \mathrm{~S}_{12} \quad\left(\begin{array}{llllll}12 & \mathrm{mS} & \mathrm{cm}^{-1}\end{array}\right)^{3}, \quad \mathrm{Li}_{7} \mathrm{P}_{3} \mathrm{~S}_{11} \quad\left(\begin{array}{llll}17 & \mathrm{mS} & \mathrm{cm}^{-1}\end{array}\right)^{4}$ and $\mathrm{Li}_{9.54} \mathrm{Si}_{1.74} \mathrm{P}_{1.44} \mathrm{~S}_{11.7} \mathrm{Cl}_{0.3}(25 \mathrm{mS} \mathrm{cm})^{-1}$. Encouraged by their excellent ion conductivity researchers have worked to demonstrate the application of sulfide SEs in solid-state secondary batteries in recent years. ${ }^{6-8}$

A typical synthesis of sulfide SEs follows routes such as high energy ball-milling ${ }^{9}$ and melt-quenching ${ }^{10}$. Limited by the technical characteristics of these synthesis methods, the particle size of synthesized SEs powders is typically several to tens of micrometers. ${ }^{11}$ Such a large particle size deteriorates the closeness of contact as well as the mixture homogeneity when SEs are composed with other components in solid-state $\mathrm{Li} / \mathrm{Li}$-ion batteries, and consequently impairs the performance of devices. ${ }^{11}$

Synthesizing sulfide SEs in liquid reaction environment provides an opportunity to reduce the particle size of SE powders. The most successful attempts of the liquid-phase synthesis of sulfide SEs are demonstrated for lithium thio-phosphate, such as $\beta-\mathrm{Li}_{3} \mathrm{PS}_{4}$ and $\mathrm{Li}_{7} \mathrm{P}_{3} \mathrm{~S}_{11}$ and its halosulfide derives such as $\mathrm{Li}_{7} \mathrm{P}_{2} \mathrm{~S}_{8} \mathrm{I}^{12-15}$ As a widely studied example, the synthesis of $\mathrm{Li}_{7} \mathrm{P}_{3} \mathrm{~S}_{11}$ in acetonitrile $(\mathrm{ACN})$ has been used to fabricate a nanoscale-mixed cathode composite of cobalt sulfide and $\mathrm{Li}_{7} \mathrm{P}_{3} \mathrm{~S}_{11}$, 
endowing the prototypical batteries with intimate contact of anode-electrolyte-cathode and 1000 cycles at room temperature. ${ }^{16}$

Despites the success on reducing particle size of sulfide SEs by liquid-phase synthesis, the ionic conductivity of the liquid-phase synthesized SEs is usually several times lower than those synthesized by solid-phase routes, ${ }^{12}$ which is intuitively ascribed to the residual solvents and impurities. ${ }^{17}$ However, how a trace amount of impurities can evidently affect the conductivity is not clearly understood. On the other hand, recent work by Calpa et al. achieved high ionic conductivity of $\mathrm{Li}_{7} \mathrm{P}_{3} \mathrm{~S}_{11}$ with a modified liquid-phase synthesis technique, ${ }^{15}$ even though a considerable amount of poor-conductive $\mathrm{Li}_{2} \mathrm{~S}$ still exists in the samples. The influence of impurities on the ionic conductivity of the liquid-phase synthesized sulfide SEs should be understood in more detail.

A recent study by Wang et al. on the liquid-phase synthesis of $\mathrm{Li}_{7} \mathrm{P}_{3} \mathrm{~S}_{11}$ in $\mathrm{ACN}$ revealed that $\mathrm{Li}_{7} \mathrm{P}_{3} \mathrm{~S}_{11}$ forms through a two-step reaction. ${ }^{18}$ The first step is the formation of a precipitate of $\mathrm{Li}_{3} \mathrm{PS}_{4} \cdot \mathrm{ACN}$ and a supernatant of an amorphous "Li $2 \mathrm{~S} \cdot \mathrm{P}_{2} \mathrm{~S}_{5}$ " phase; Second, solid-state conversion of the two phases occurs. Inspired by this work, it is reasonable to expect that the ionic conductivity of $\operatorname{Li} 7 \mathrm{P}_{3} \mathrm{~S}_{11}$ could be affected by the precipitate/supernatant ratio during liquid-phase synthesis. In this work, the precipitate/supernatant ratio during liquid-phase synthesis of $\mathrm{Li}_{7} \mathrm{P}_{3} \mathrm{~S}_{11}$ is intentionally controlled by removing or adding aliquots of supernatant from/into the suspension, and its influence on the phase structure, morphology and ionic conductivity of the synthesized SEs is studied. The results reveal how the morphology 
of the impurities evidently affect the ionic conductivity of the resultant solid electrolytes. It also helps us to better understand our previously reported phenomena observed during solvent-assisted mechano-synthesis of $\mathrm{Li}_{7} \mathrm{P}_{3} \mathrm{~S}_{11},{ }^{19}$ which is a promising technique for large-scale production due to its industrial compatibility and evidently reduced reaction time.

\section{Experimental}

The chemical agents used were $\mathrm{Li}_{2} \mathrm{~S}$ (99.9\%, Alfa Aesar), $\mathrm{P}_{2} \mathrm{~S}_{5}$ (99\%, Qingdao Yurui Ltd.), acetonitrile ( $\geqslant 99.5 \%$, Aladdin) and dimethoxyethane ( $\geqslant 99.5 \%$, Aladdin). All the chemicals were used after receiving from the suppliers, without further purification.

\subsection{Synthesis in acetonitrile}

The starting segment of the liquid-phase synthesis of $\mathrm{Li}_{7} \mathrm{P}_{3} \mathrm{~S}_{11}$ in acetonitrile (ACN) followed a typical procedure reported in the literature. ${ }^{18,20}$ Briefly, $1 \mathrm{~g}$ mixture of $\mathrm{Li}_{2} \mathrm{~S}$ and $\mathrm{P}_{2} \mathrm{~S}_{5}$ with molar ratio of $7: 3$ was dispersed in $20.0 \mathrm{ml} \mathrm{ACN}$, resulting in a yellowish suspension. The suspension was stirred for 3 days at room temperature, and finally turned into a purely white suspension.

The obtained precursor suspension was then centrifugated at $6000 \mathrm{rpm}$ for $4 \mathrm{~min}$. The suspension was divided into white precipitates and a yellowish supernatant. Aliquots of supernatant were removed/added from/into the precursor so that the precipitate/supernatant ratio was controlled. For each aliquot, $0.8 \mathrm{ml}$ supernatant was transferred by a pipettor. Therefore, the samples are denoted as $+n * 0.8 \mathrm{ml}$ or $-\mathrm{n} * 0.8$ $\mathrm{ml}$, where $\mathrm{n}$ is the number of aliquots and $+/$ - represents adding/removing supernatant. 
After the transfer of partial supernatant, the precursor was dispersed again to form homogeneous suspension. The suspension was then dried at room temperature in a mortar. Continuous stirring was conducted during the drying with a pestle, to avoid undesired phase separation.

All of the procedures in 2.1 and 2.2 were conducted in argon atmosphere $\left(\mathrm{O}_{2}<0.5\right.$ ppm, $\left.\mathrm{H}_{2} \mathrm{O}<0.5 \mathrm{ppm}\right)$.

Finally, the obtained powders were vacuum-dried at $200{ }^{\circ} \mathrm{C}$ for 2 hours and then heat-treated at $250{ }^{\circ} \mathrm{C}$ for 1 hour in argon atmosphere $(0.08 \mathrm{MPa})$, resulting in the formation of sulfide SEs.

\subsection{Synthesis in dimethoxyethane}

The liquid-phase synthesis of $\mathrm{Li}_{7} \mathrm{P}_{3} \mathrm{~S}_{11}$ in dimethoxyethane (DME) followed the procedure called "solvent-assisted ball milling" as described in our previous publication. ${ }^{19}$ It can evidently reduce the reaction time from several days to less than 8 hours. Briefly, $4 \mathrm{~g}$ mixture of $\mathrm{Li}_{2} \mathrm{~S}$ and $\mathrm{P}_{2} \mathrm{~S}_{5}$ (molar ratio $7: 3$ ) as well as $16.0 \mathrm{ml}$ DME was put into a $45 \mathrm{ml} \mathrm{WC} \mathrm{jar} \mathrm{with} \mathrm{three} \mathrm{WC} \mathrm{grinding} \mathrm{balls}(\varphi=10 \mathrm{~mm})$. Then ball milling was conducted at $450 \mathrm{rpm}$ using a planetary ball mill apparatus (Pulverisette 7, Fritsch GmbH, Germany). The duration of ball-milling was $8 \mathrm{~h}$. The resultant white slurry was further diluted with $14.0 \mathrm{ml} \mathrm{DME}$ to form a suspension.

Then, two samples were prepared. For the first, the suspension was directly dried at room temperature by using mortar \& pestle. For the second, the suspension was centrifuged and the precipitates were washed and gathered. Both of them were then vacuum-dried at $180{ }^{\circ} \mathrm{C}$ for 2 hours and heat-treated at $230{ }^{\circ} \mathrm{C}$ for 4 hours to get the 
sulfide SEs.

\subsection{Characterization}

X-ray diffraction (D8 Advance, Bruker AXS GmbH, Germany) was used to study the influence of the precipitate/supernatant ratio on the phase structure of the resultant sulfide SEs. The types of ion groups in the SEs were characterized by Raman spectra, which were recorded by a Raman spectrometer (inVia, Renishaw Inc., UK) with a 532 nm DPSS laser as the light source. To protect the samples from exposure to air humidity, they were mounted in the sample holder and sealed by polyimide cover film in the glove box prior to XRD and Raman characterization. The morphology of the SE powders was recorded by a scanning electron microscope (Zeiss supra 55, Carl Zeiss GmbH, Germany). The scanning electron microscope was equipped with an energy dispersive X-ray microanalyzer (QUANTAX 200, Bruker AXS GmbH, Germany), which was used to characterize the composition of the samples.

The room-temperature ionic conductivity was measured using an $\mathrm{AC}$ impedance method in an argon filled glove box $\left(\mathrm{O}_{2}<0.5 \mathrm{ppm}, \mathrm{H}_{2} \mathrm{O}<0.5 \mathrm{ppm}\right)$, using a frequency response analyzer (Solartron 1260A, Solartron Analytical Inc., UK). For the measurement, the SE powders were cold-pressed into pellets $(15 \mathrm{~mm}$ diameter and $\sim 0.7 \mathrm{~mm}$ thickness) under $330 \mathrm{MPa}$ pressure, with carbon paint on both sides as the blocking electrodes.

\section{Results\& discussion}

\subsection{Characterization of the precipitate and supernatant}

During synthesis the sulfide SEs in ACN, the precipitate and supernatant are 
collected from the suspension by centrifugation and room-temperature drying. The as-dried precipitate is purely white and the as-dried supernatant is light yellow. As shown in Figure 1(a), XRD reveals that the as-dried supernatant is amorphous. Conversely, the as-dried precipitate is crystallized, and its diffraction peaks are in good accordance with those of $\mathrm{ACN}$-solvated $\mathrm{Li}_{3} \mathrm{PS}_{4}{ }^{21}$
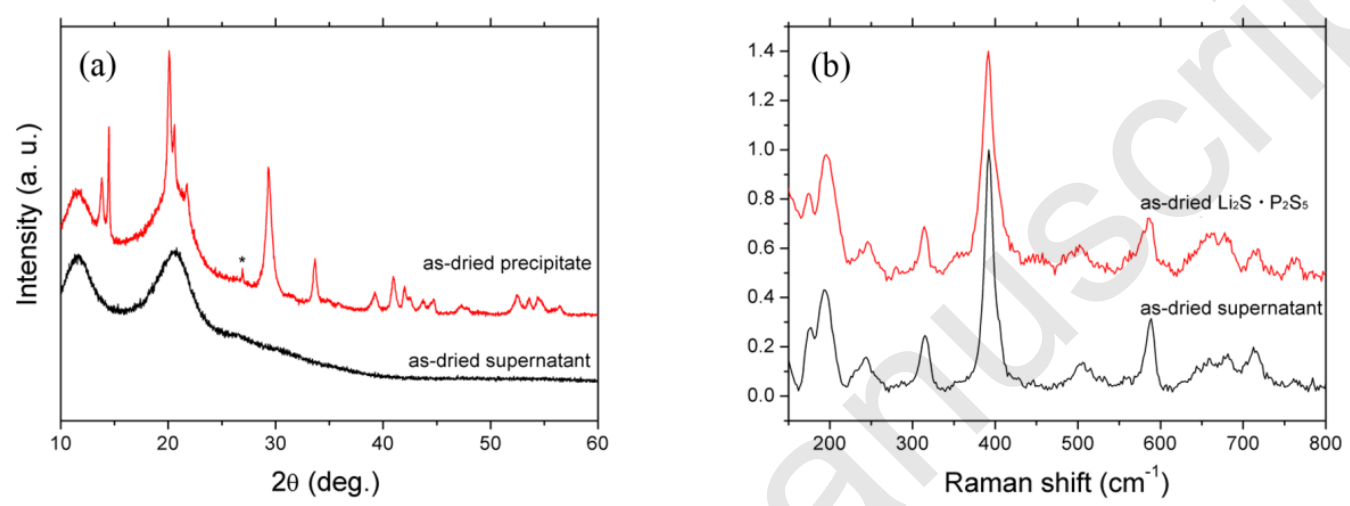

Figure 1.(a) XRD patterns of the as-dried precipitate and supernatant which are collected from the suspension during synthesizing the sulfide SEs in ACN. The small peak marked by asterisk is attributed to a trace amount of $\mathrm{Li}_{2} \mathrm{~S}$. The two broad peaks between $10^{\circ}-25^{\circ}$ are attributed to the polyimide cover film.(b) Raman spectrum of the as-dried supernatant in comparison with that of the dry product from the ACN solution of $\mathrm{Li}_{2} \mathrm{~S} \cdot \mathrm{P}_{2} \mathrm{~S}_{5}$.

The composition of the as-dried precipitate and supernatant is characterized by EDS. The results are listed in Table 1. It reveals that both components contain $\mathrm{S}$ and $\mathrm{P}$, and more sulfur is detected in the precipitate. However, due to the insensitivity of EDS to light elements such as $\mathrm{P}$ and $\mathrm{S}$, the absolute value is not precise. Because XRD reveals that the precipitate is $\mathrm{ACN}$-solvated $\mathrm{Li}_{3} \mathrm{PS}_{4}$, it can be assumed that the $\mathrm{S}: \mathrm{P}$ ratio of the precipitate should be 4.0:1. Based on this assumption, the EDS results are corrected and the S:P ratio of the supernatant turns out to be 2.9:1, approaching that of a "Li2 $\mathrm{S} \cdot \mathrm{P}_{2} \mathrm{~S}_{5}$ " phase(3:1).

Table 1 EDS analysis of the as-dried precipitate and supernatant which are collected from the 
suspension during synthesizing the sulfide SEs in ACN.

\begin{tabular}{ccccc}
\hline & P\% & S\% & S:P & corrected S:P* $^{*}$ \\
\hline Precipitate & $24 \%$ & $76 \%$ & $3.2: 1$ & $4.0: 1$ \\
Supernatant & $30 \%$ & $70 \%$ & $2.3: 1$ & $2.9: 1$ \\
\hline
\end{tabular}

* correction is made by assuming that the S:P ratio of the precipitate should be fixed at 4.0:1.

To further confirm the phase structure of the supernatant, an amorphous "Li2 $\mathrm{S}_{2} \cdot \mathrm{P}_{2} \mathrm{~S}_{5}$ " phase is deliberately prepared as a reference. By stirring a mixture of $\mathrm{Li}_{2} \mathrm{~S}$ and $\mathrm{P}_{2} \mathrm{~S}_{5}$ with molar ratio of $1: 1$ in $\mathrm{ACN}$ at room temperature, a transparent yellowish solution can be obtained. The solution is subsequently dried at room temperature. The resultant " $\mathrm{Li}_{2} \mathrm{~S} \cdot \mathrm{P}_{2} \mathrm{~S}_{5}$ " powder is confirmed to be amorphous by XRD. The Raman spectra of the as-dried supernatant and the " $\mathrm{Li}_{2} \mathrm{~S} \cdot \mathrm{P}_{2} \mathrm{~S}_{5}$ " powder are compared in Figure 1(b). The two spectra are almost identical, further confirming that the supernatant is composed of the " $\mathrm{Li}_{2} \mathrm{~S} \cdot \mathrm{P}_{2} \mathrm{~S}_{5}$ " phase.

In summary, during the liquid-phase synthesis of $\mathrm{Li}_{7} \mathrm{P}_{3} \mathrm{~S}_{11}$ in $\mathrm{ACN}$ at room temperature, a supernatant of " $\mathrm{Li}_{2} \mathrm{~S} \cdot \mathrm{P}_{2} \mathrm{~S}_{5}$ " and a precipitate of $\mathrm{ACN}$-solvated $\mathrm{Li}_{3} \mathrm{PS}_{4}$ exist in the precursor suspension. Our result coincides with the mechanism reported by Wang et al. when synthesizing $\mathrm{Li}_{7} \mathrm{P}_{3} \mathrm{~S}_{11}$ in $\mathrm{ACN}$ at $50{ }^{\circ} \mathrm{C} .{ }^{18}$

Assuming that all " $\mathrm{Li} 2 \mathrm{~S} \cdot \mathrm{P}_{2} \mathrm{~S}_{5}$ " dissolves in $20.0 \mathrm{ml} \mathrm{ACN}$ and all ACN-solvated $\mathrm{Li}_{3} \mathrm{PS}_{4}$ precipitates, we can estimate the nominal composition of the final SEs, as shown in Table 2. It should be noted that even though a notable amount of supernatant has been transferred from/into the suspension, the change of the estimated composition of the SEs is still not evident, making it difficult to be clearly detected by EDS.

Table 2. Nominal composition of the lithium thiophosphate SEs prepared in ACN, 
represented by the molar percentage of $\mathrm{Li}_{2} \mathrm{~S}$.

\begin{tabular}{ccccccccc}
\hline Sample & $\begin{array}{c}\mathbf{+ 8} \\
* \mathbf{0 . 8 m l}\end{array}$ & $\begin{array}{c}\mathbf{+ 4} \\
* \mathbf{0 . 8 m l}\end{array}$ & $\begin{array}{c}\mathbf{+ 2} \\
* \mathbf{0 . 8 m l}\end{array}$ & $\mathbf{0}$ & $\begin{array}{c}\mathbf{- 2} \\
* \mathbf{0 . 8 m l}\end{array}$ & $\begin{array}{c}\mathbf{- 4} \\
* \mathbf{0 . 8 m l}\end{array}$ & $\begin{array}{c}\mathbf{- 6} \\
* \mathbf{0 . 8 m l}\end{array}$ & $\begin{array}{c}\mathbf{- 8} \\
* \mathbf{0 . 8 m l}\end{array}$ \\
\hline $\mathbf{L i} \mathbf{2} \mathbf{S} \%$ & 68.8 & 69.4 & 69.7 & 70.0 & 70.3 & 70.7 & 71.0 & 71.4 \\
\hline
\end{tabular}

\subsection{Influence of precipitate/supernatant ratio on structureinACN}

Figure 2 shows the XRD patterns of the sulfide SEs prepared in ACN with different precipitate/supernatant ratios. According to the characteristics of the patterns, the precipitate/supernatant ratio can be clearly divided into three regions. In the first region where the supernatant is excess in the precursor suspension (colored by yellow), both the signals from $\mathrm{Li}_{4} \mathrm{P}_{2} \mathrm{~S}_{6}$ and $\mathrm{Li}_{7} \mathrm{P}_{3} \mathrm{~S}_{11}$ are evident. In the second region where the deviation of the precipitate/supernatant ratio is small (colored by grey), $\mathrm{Li}_{7} \mathrm{P}_{3} \mathrm{~S}_{11}$ is the only major phase detected by XRD. However, a small quantity of $\mathrm{Li}_{4} \mathrm{P}_{2} \mathrm{~S}_{6}$ or a thio-LISICON III phase may still exist. In the third region where the precipitate is excess (colored by blue), the thio-LISICON III phase which possesses a similar crystalline structure with $\beta-\mathrm{Li}_{3} \mathrm{PS}_{4}$ becomes the major phase.

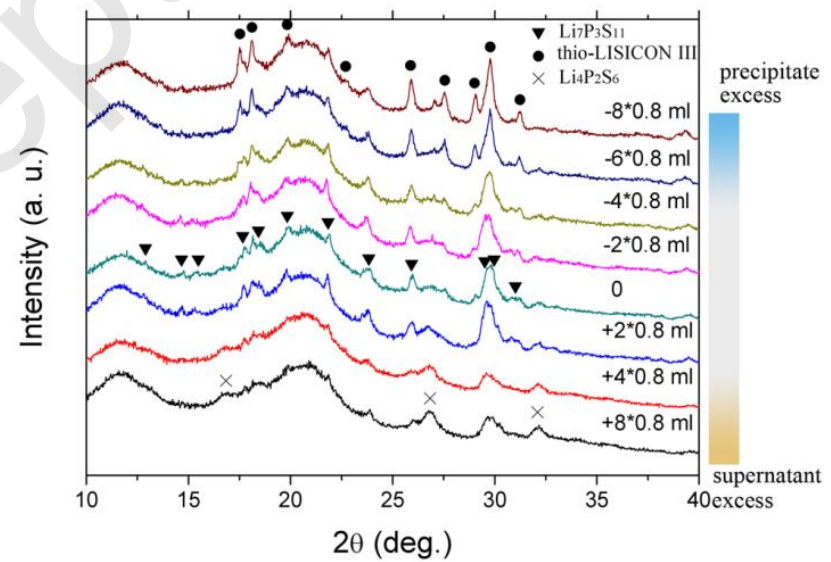

Figure2. XRD patterns of the sulfide SEs prepared in ACN with different precipitate/supernatant ratios. The precipitate/supernatant ratio is controlled by adding/removing aliquots of supernatant into/from the precursor suspension, whose quantity is denoted by the sample names.

The formation of the thio-LISICON III phase in the precipitate-excess samples is 
clearly associated with the excess $\mathrm{Li}_{3} \mathrm{PS}_{4} \cdot \mathrm{ACN}$ that has not been reacted with " $\mathrm{Li} 2 \mathrm{~S} \cdot \mathrm{P}_{2} \mathrm{~S}_{5}$ ". It has been widely observed that the solvated $\mathrm{Li}_{3} \mathrm{PS}_{4}$ formed during the liquid-phase synthesis finally turns into $\beta-\mathrm{Li}_{3} \mathrm{PS}_{4}$ or precisely a thio-LISICON III phase after heat-treatment. ${ }^{13,18,21,22}$

The formation of $\mathrm{Li}_{4} \mathrm{P}_{2} \mathrm{~S}_{6}$ should be associated with the excess " $\mathrm{Li}_{2} \mathrm{~S} \cdot \mathrm{P}_{2} \mathrm{~S}_{5}$ " in the supernatant-excess samples. $\mathrm{Li}_{4} \mathrm{P}_{2} \mathrm{~S}_{6}$ is a compound showing high thermal stability among the lithium thiophosphate family. It has been widely observed that the metastable phases such as $\mathrm{Li}_{7} \mathrm{P}_{3} \mathrm{~S}_{11}$ degrade into $\mathrm{Li}_{4} \mathrm{P}_{2} \mathrm{~S}_{6}$ at high temperature. ${ }^{23-25}$ This degradation is attributed to the transition of the pyro-thiophosphate anion $\mathrm{P}_{2} \mathrm{~S}_{7}{ }^{4-}$ to the meta-thiodiphosphate anion $\mathrm{P}_{2} \mathrm{~S}_{6}{ }^{-4}{ }^{26}$ indicating that the P-P homo-bond is more stable than the P-S-P bridge sulfur structure at high temperature.

It has been reported that the major building unit in $50 \mathrm{Li}_{2} \mathrm{~S}-50 \mathrm{P}_{2} \mathrm{~S}_{5}$ glass is $\left(\mathrm{PS}_{3}^{-}\right)_{\mathrm{n}}$ chains. ${ }^{27}$ Since the solvated amorphous " $\mathrm{Li}_{2} \mathrm{~S} \cdot \mathrm{P}_{2} \mathrm{~S}_{5}$ " has the same $\mathrm{Li}_{2} \mathrm{~S}: \mathrm{P}_{2} \mathrm{~S}_{5}$ ratio of 1:1, it can be assumed that the $\left(\mathrm{PS}_{3}{ }^{-}\right)_{\mathrm{n}}$ chains are also formed in the solution of " $\mathrm{Li}_{2} \mathrm{~S} \cdot \mathrm{P}_{2} \mathrm{~S}_{5}$ " by the reaction describe as follows:

$\mathrm{n} / 2 \mathrm{Li}_{2} \mathrm{~S}+\mathrm{n} / 2 \mathrm{P}_{2} \mathrm{~S}_{5} \rightarrow \mathrm{n} \mathrm{Li}^{+}+\left(\mathrm{PS}_{3}{ }^{-}\right)_{\mathrm{n}}$

Through the reaction, the nonpolar molecule $\mathrm{P}_{2} \mathrm{~S}_{5}$ (or precisely $\mathrm{P}_{4} \mathrm{~S}_{10}$ ) turns into the polar $\left(\mathrm{PS}_{3}{ }^{-}\right)_{n}$ chains, so that the solubility in the polar solvent $\mathrm{ACN}$ is enhanced. Additionally, comparing with other thiophosphate anions, $\left(\mathrm{PS}_{3}{ }^{-}\right)_{\mathrm{n}}$ has more scattered negative charge distribution, resulting in weaker ionic bonds with $\mathrm{Li}^{+}$so the dissolution in $\mathrm{ACN}$ is easier.

Assuming that $\left(\mathrm{PS}_{3}{ }^{-}\right)_{n}$ chain is a major building unit of the amorphous " $\mathrm{Li}_{2} \mathrm{~S} \cdot \mathrm{P}_{2} \mathrm{~S}_{5}$ " 
phase, it can be concluded that a large amount of P-S-P bridge sulfur structures exist in the precursor, which will be turned into P-P homo-bonds after heat-treatment at $250{ }^{\circ} \mathrm{C}$, leading to the formation of $\mathrm{Li}_{4} \mathrm{P}_{2} \mathrm{~S}_{6}$ as shown by XRD in Figure 2.

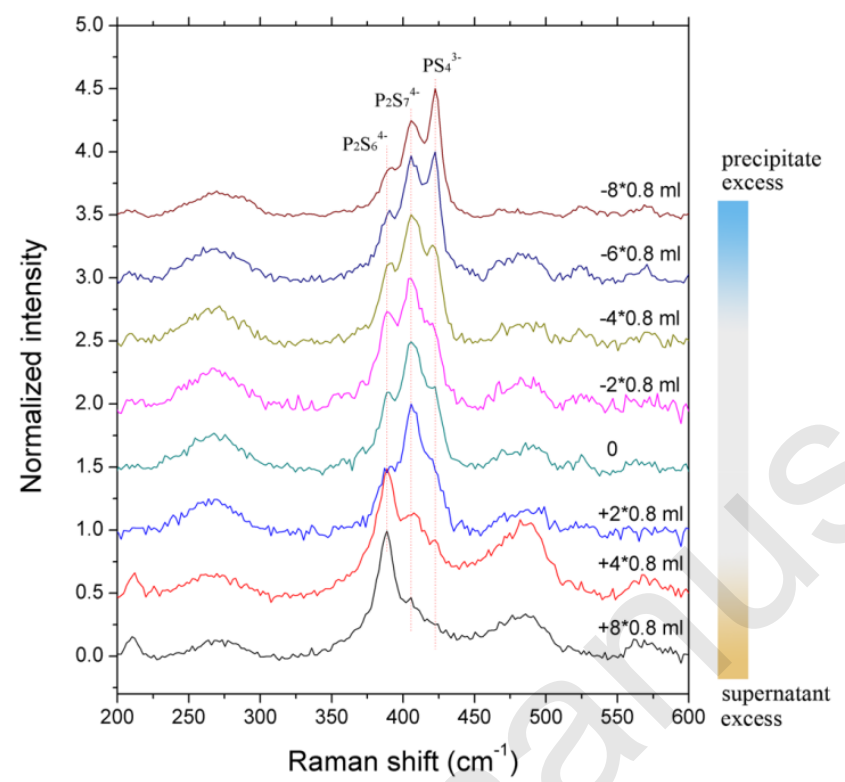

Figure 3. Raman spectra of the sulfide SEs prepared in ACN, showing the evolution of ratio between the three typical ion groups in lithium thiophosphates when precipitate/supernatant ratio of the precursor suspension gradually changes.

The Raman spectra of the sulfide SEs prepared in ACN with different precipitate/supernatant ratios are shown in Figure 3. All the spectra contain three major Raman signals round $400 \mathrm{~cm}^{-1}$ which are attributed to the typical anions in lithium thiophosphates: hypo-thiodiphosphate $\left(\mathrm{P}_{2} \mathrm{~S}_{6}{ }^{4-}, 392 \mathrm{~cm}^{-1}\right)$, pyro-thiophosphate $\left(\mathrm{P}_{2} \mathrm{~S}_{7}{ }^{4-}, 406 \mathrm{~cm}^{-1}\right)$ and ortho-thiophosphate $\left(\mathrm{PS}_{4}{ }^{3-}, 406 \mathrm{~cm}^{-1}\right)$. Corresponding to the XRD patterns, the characteristics of Raman spectra can also divide the precipitate/supernatant ratio into three regions. In the supernatant-excess region (colored by yellow), the signal from $\mathrm{P}_{2} \mathrm{~S}_{6}{ }^{4-}$ is predominant, as a result of the existence of a large amount of $\mathrm{Li}_{4} \mathrm{P}_{2} \mathrm{~S}_{6}$. In the region where the deviation of the precipitate/supernatant ratio is small (colored by grey), the main signal is from $\mathrm{P}_{2} \mathrm{~S}_{7}{ }^{4-}$, 
which is the characteristic anion of $\mathrm{Li}_{7} \mathrm{P}_{3} \mathrm{~S}_{11}$. Finally, in the precipitate-excess region (colored by blue), the signal from $\mathrm{PS}_{4}{ }^{3-}$ becomes evident, corresponding to the existence of the thio-LISICON III phase as revealed by XRD.

It is noted that two Raman peaks around $212 \mathrm{~cm}^{-1}$ and $483 \mathrm{~cm}^{-1}$ are more evident in the supernatant-excess region. The two peaks show close position and similar profile to the major signals of polymerized sulfur, which are assigned to two $\mathrm{A}_{1}$ modes. ${ }^{28}$ These Raman signals of S-S bond is probably associated with the decomposition from " $\mathrm{Li}_{2} \mathrm{~S} \cdot \mathrm{P}_{2} \mathrm{~S}_{5}$ ” to $\mathrm{Li}_{4} \mathrm{P}_{2} \mathrm{~S}_{6}$ which releases sulfur.

The SEM images of the sulfide SEs prepared in ACN with different precipitate/supernatant ratios are shown in Figure 4. It can be seen that the morphology gradually changes with the precipitate/supernatant ratio. For the SEs in supernatant-excess region (a-b), a paste-like component wrapping the particles is observed. Viewing that the soluble amorphous " $\mathrm{Li}_{2} \mathrm{~S} \cdot \mathrm{P}_{2} \mathrm{~S}_{5}$ " tends to form a gel-like substance after drying, ${ }^{18}$ it is reasonably to assign the paste-like component to $\mathrm{Li}_{4} \mathrm{P}_{2} \mathrm{~S}_{6}$ that is decomposed from the excess " $\mathrm{Li}_{2} \mathrm{~S} \cdot \mathrm{P}_{2} \mathrm{~S}_{5}$ ". For the SEs in the region where the deviation of the precipitate/supernatant ratio is small (c-f), large pieces of the paste-like component disappear. Instead, the aggregates of small particles sized of hundreds of nanometers becomes the characteristic morphology. In precipitate-excess region (g-h), even small particles sized of tens of nanometers can be observed, and the aggregation of the particles becomes less evident. Considering the results of XRD and Raman in the precipitate-excess region, it could be assumed that the appearing of small particles and the amelioration of aggregation are attributed to the deficiency of 
gel-like " $\mathrm{Li}_{2} \mathrm{~S} \cdot \mathrm{P}_{2} \mathrm{~S}_{5}$ " in this region.

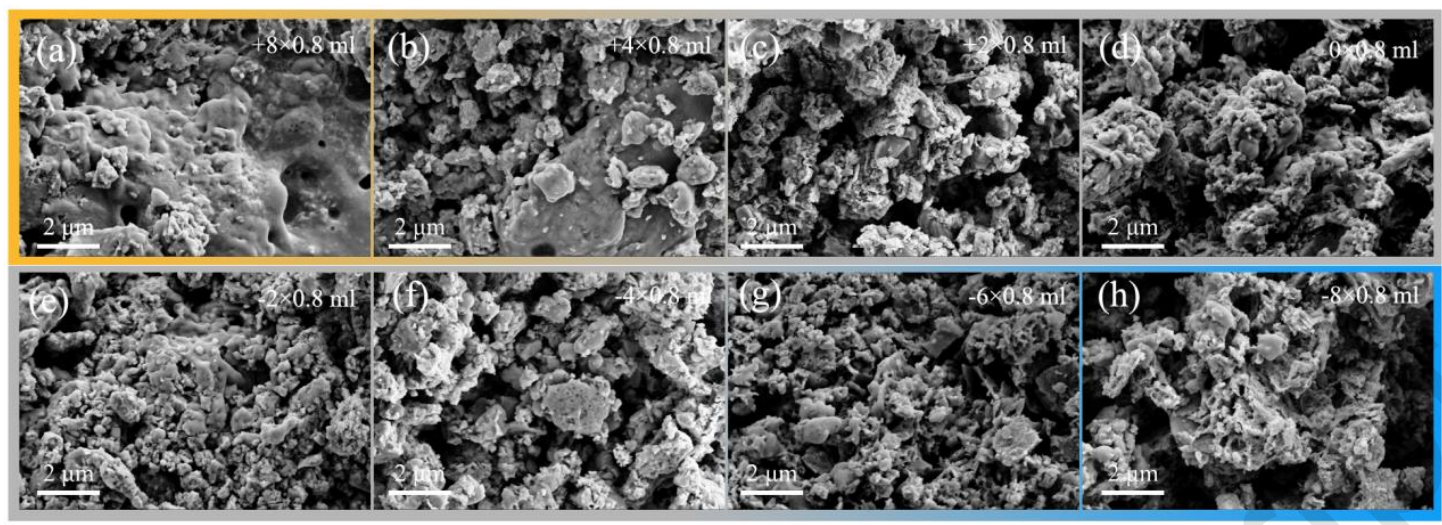

Figure4. SEM images of the sulfide SEs prepared in ACN with different precipitate/supernatant ratios.

\subsection{Influence of precipitate/supernatant ratio on ionic conductivity inACN}

Figure 5 shows the impedance spectra of the samples prepared in ACN with different precipitate/supernatant ratios. All the spectra consist of a high-frequency arc and a low-frequency tail. The arc is attributed to the interfacial capacitance and interfacial resistance in parallel, while the tail is attributed to the polarization near the electrolyte/electrode interface. ${ }^{29}$ The total resistance $R_{\text {tot }}$ (bulk resistance plus interfacial resistance) can be obtained at the low frequency end of the arc. The ionic conductivity of the samples is calculated by the following equation:

$$
\sigma=d / A R_{\mathrm{tot}}
$$

where $\mathrm{d}$ an $\mathrm{A}$ are the thickness and area of the samples, respectively. 


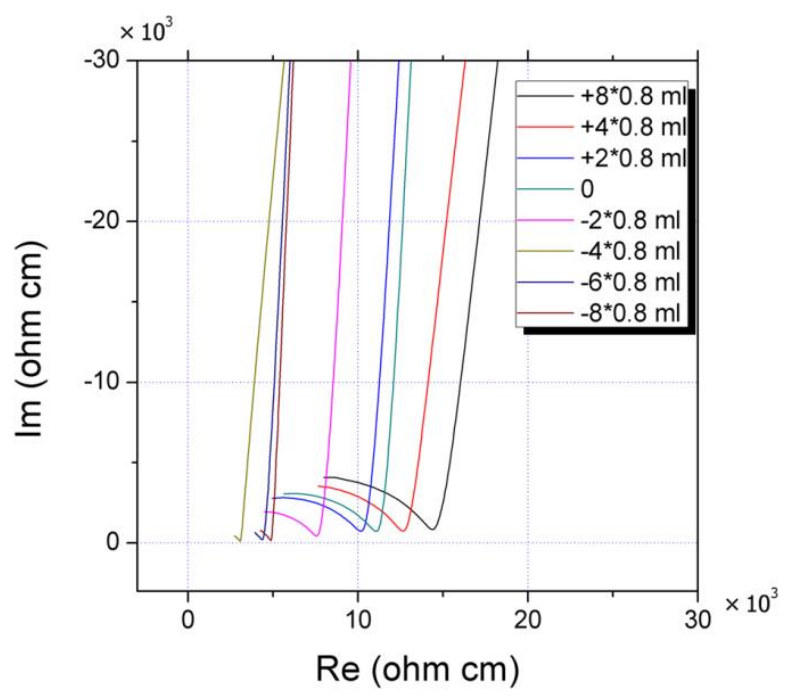

Figure 5. Impendence spectra of the sulfide SEs prepared in ACN with different precipitate/supernatant ratios.

As the low frequency end of the arc in Figure 5 ranges from $3.1 \times 10^{3} \mathrm{ohm} \mathrm{cm}$ to $1.4 \times 10^{4} \mathrm{ohm} \mathrm{cm}$, it can be confirmed that the precipitate/supernatant ratio evidently affects the ionic conductivity of the resultant SEs. The dependence of the ionic conductivity on the precipitate/supernatant ratio is further quantitively presented in Figure 6. When the ratio changes, the ionic conductivity of SEs evolves regularly. In supernatant-excess region, the conductivity shows the lowest value. The conductivity tends to increase by reducing the amount of supernatant, and reaches the maximum in the sample $-4 * 0.8 \mathrm{ml}$, of $3.3 \times 10^{-4} \mathrm{~S} \mathrm{~cm}^{-1}$. Thereafter, the conductivity turns to decrease. 


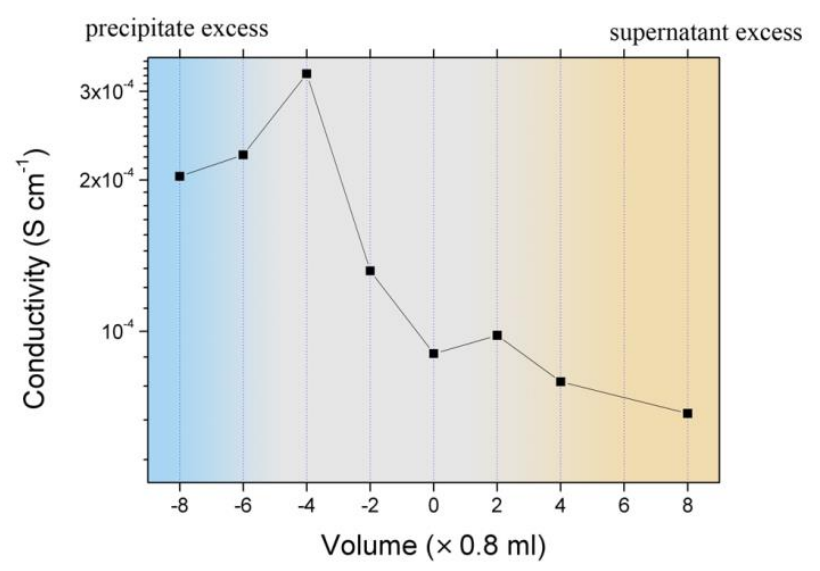

Figure 6. The dependence of the ionic conductivity on the added/removed volume of the supernatant into/from the precursor suspension.

It is worth noting that the maximum ionic conductivity is not achieved in the sample prepared from the virginal precursor suspension, which has a nominal $\mathrm{Li}_{2} \mathrm{~S} \%$ of $70.0 \%$. Instead, the highest ionic conductivity is achieved in the sample $-4 * 0.8 \mathrm{ml}$ with a nominal $\mathrm{Li}_{2} \mathrm{~S} \%$ of $70.7 \%$. The phenomenon that a slight deviation to a $\mathrm{Li}_{2} \mathrm{~S}$-rich composition results in higher conductivity when preparing $\mathrm{Li}_{7} \mathrm{P}_{3} \mathrm{~S}_{11}$ in $\mathrm{ACN}$ has also been reported by Calpa et al. in a recent publication. ${ }^{30}$ Figure 7 illustrates how the precipitate/supernatant ratio affects the phase structure, the morphology and consequently the ionic conductivity of the SEs when preparing $\mathrm{Li}_{7} \mathrm{P}_{3} \mathrm{~S}_{11}$ in $\mathrm{ACN}$. In the supernatant-excess region, a large amount of gel-like " $\mathrm{Li}_{2} \mathrm{~S} \cdot \mathrm{P}_{2} \mathrm{~S}_{5}$ " wraps the particles of $\mathrm{Li}_{3} \mathrm{PS}_{4} \cdot \mathrm{ACN}$. The following heat treatment leads to the solid reaction between the two phases and to produce $\mathrm{Li}_{7} \mathrm{P}_{3} \mathrm{~S}_{11}$. Since the solid reaction progresses from the interface to the inside, $\mathrm{Li}_{4} \mathrm{P}_{2} \mathrm{~S}_{6}$ produced from the excess " $\mathrm{Li} 2 \mathrm{~S} \cdot \mathrm{P}_{2} \mathrm{~S}_{5}$ " will become a shell which covers the resultant $\mathrm{Li}_{7} \mathrm{P}_{3} \mathrm{~S}_{11}$ particles, leading to aggregation (as shown by SEM in Figure 4). Due to the low ionic conductivity of $\mathrm{Li}_{4} \mathrm{P}_{2} \mathrm{~S}_{6}\left(\sim 10^{-11} \mathrm{~S}\right.$ $\mathrm{cm}^{-1}$ by calculation ${ }^{31}$ and $\sim 10^{-7} \mathrm{~S} \mathrm{~cm}^{-1}$ by experiment ${ }^{32}$ ) and its paste-like morphology, it notable increases the interfacial resistance of the SEs, hinders the ion transfer 
between $\mathrm{Li}_{7} \mathrm{P}_{3} \mathrm{~S}_{11}$ particles, and results in a low total ionic conductivity. In the precipitate-excess region, " $\mathrm{Li} 2 \mathrm{~S} \cdot \mathrm{P}_{2} \mathrm{~S}_{5}$ " is exhausted and the excess $\mathrm{Li}_{3} \mathrm{PS}_{4} \cdot \mathrm{ACN}$ turns into the thio-LISICON III phase. Again, due to the diffuse feature of solid reaction, the thio-LISICON III impurities tend to stay in the core of the $\mathrm{Li}_{7} \mathrm{P}_{3} \mathrm{~S}_{11}$ particles, so that their negative influence on the total ionic conductivity is not evident.

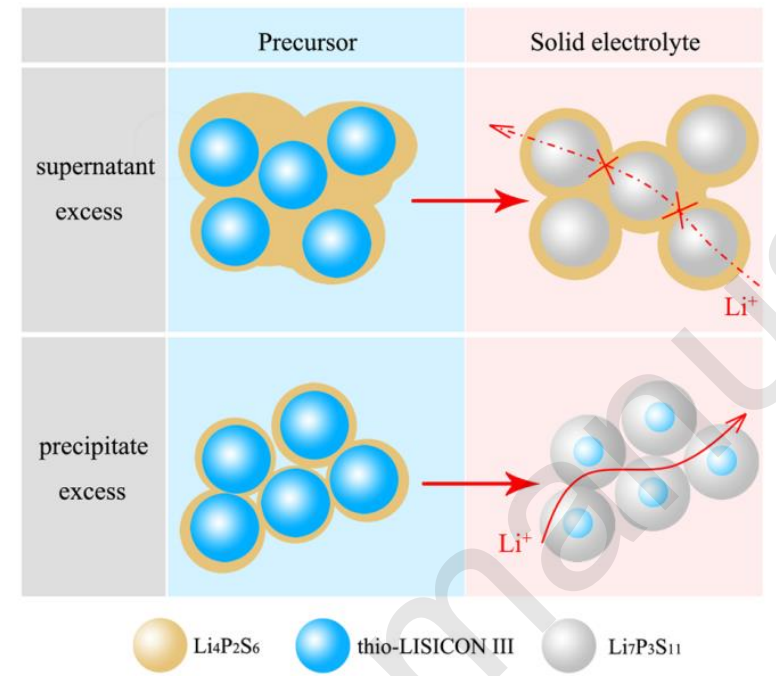

Figure 7. Schemeof the influence of the precipitate/supernatant ratio on the properties of SEs when preparing $\mathrm{Li}_{7} \mathrm{P}_{3} \mathrm{~S}_{11}$ in $\mathrm{ACN}$. The component in the SEs and its corresponding precursor share the same symbol.

During the liquid phase synthesis of $\mathrm{Li}_{7} \mathrm{P}_{3} \mathrm{~S}_{11}$ in $\mathrm{ACN}$, it is usually a difficult task to maintain the homogeneity of the precursor suspension during drying. Consequently, partial precursor may be in the supernatant-excess region, which is detrimental for the ionic conductivity. Slightly increasing $\mathrm{Li}_{2} \mathrm{~S} \%$ to shift the composition into the precipitate-excess region inhabits the formation of the poorly ionic conductive phase $\mathrm{Li}_{4} \mathrm{P}_{2} \mathrm{~S}_{6}$ around $\mathrm{Li}_{7} \mathrm{P}_{3} \mathrm{~S}_{11}$ particles, at the expense of the formation of the thio-LISICON III impurities in the core. The overall effect is that the total ionic conductivity is improved, as what is observed in this work. The more homogeneous the suspension can be kept during drying, through control of drying speed and 
surrounding environment, the less composition is expected.

\subsection{How about other solvents?}

According to the $\mathrm{ACN}$ results, the precipitate/supernatant ratio during liquid-phase synthesis of solid electrolyte $\mathrm{Li}_{7} \mathrm{P}_{3} \mathrm{~S}_{11}$ in $\mathrm{ACN}$ has a notable influence on the phase structure, the morphology and consequently the ionic conductivity of the products. Now the question is, whether this conclusion is adoptable for synthesis in other solvents. Here we choose DME because it is a typical ether used for liquid-phase synthesis of lithium thiophosphates.

The liquid-phase synthesis of $\mathrm{Li}_{7} \mathrm{P}_{3} \mathrm{~S}_{11}$ in DME follows our previously reported procedure "solvent-assisted ball milling" due to its industrial compatibility and evidently reduced reaction time. The obtained suspension is directly dried and heat-treated to form the SE, or centrifugated to get the precipitate followed by converting the washed precipitate into the SE.

Our previous study reveals the existence of two phases, an amorphous phase and a solvated $\mathrm{Li}_{3} \mathrm{PS}_{4}$, in the suspension prepared by DME-assisted ball-milling. ${ }^{19}$ Therefore, a two-step mechanism similar to that in ACN also governs the formation of $\mathrm{Li}_{7} \mathrm{P}_{3} \mathrm{~S}_{11}$ in DME. Surprisingly, both SEs prepared from the whole suspension and the precipitate are mainly composed of $\operatorname{Li}_{7} \mathrm{P}_{3} \mathrm{~S}_{11}$ as shown by XRD (Figure 8 ). It implies that the amorphous phase also exists in the precipitation. We put the precipitate prepared by DME-assisted ball-milling into ACN. The supernatant rapidly becomes yellow while the precipitate is still white. It further confirms that the amorphous phase also precipitates in DME. 


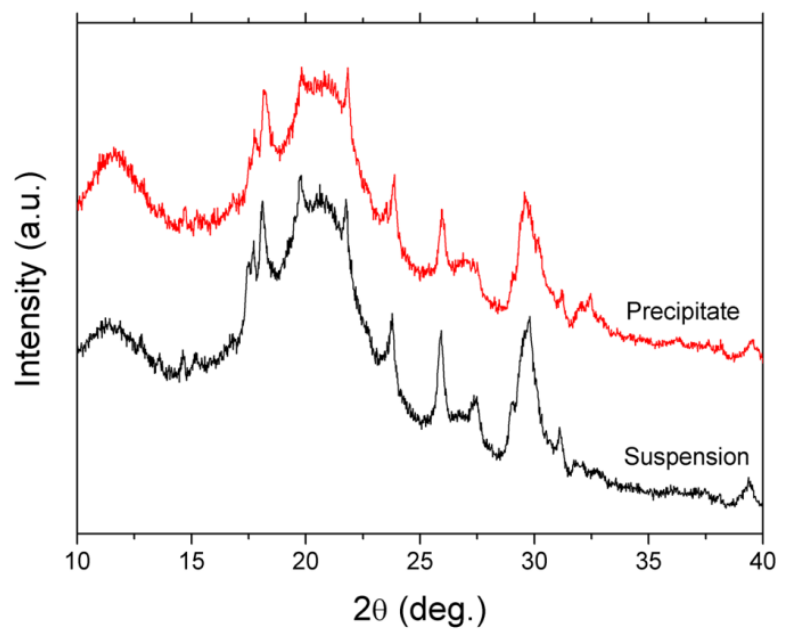

Figure 8. XRD patterns of the obtained SEs after drying and heat-treating the whole suspension or only the precipitate, during the solvent-assisted ball milling of $\mathrm{Li}_{7} \mathrm{P}_{3} \mathrm{~S}_{11}$ in DME.

As is well known, the dielectric property and the acidity/basicity of solvents are two key factors which govern the interaction between polar solvent and solute. ${ }^{33}$ Solvents with high dielectric constant can stabilize highly charged species, while solvents with high acidity/basicity tend to dissolve the species rich of basic/acidic sites. ${ }^{34}$ The amorphous "Li2 $\mathrm{S} \cdot \mathrm{P}_{2} \mathrm{~S}_{5}$ " phase, as discussed above, contains charged thiophosphate anions. Meanwhile, thiophosphate anions lack vacant nonbonding orbitals to provide acidic sites. Therefore, " $\mathrm{Li}_{2} \mathrm{~S} \cdot \mathrm{P}_{2} \mathrm{~S}_{5}$ " tends to be dissolved in solvents with high dielectric constant. Since the dielectric constant of ACN $\left(\varepsilon_{r}=35.9\right)$ is much higher than that of DME $\left(\varepsilon_{r}=7.2\right)$, the amorphous " $\mathrm{Li}_{2} \mathrm{~S} \cdot \mathrm{P}_{2} \mathrm{~S}_{5}$ " phase can be dissolved in ACN but not in DME.

In the literature, the ionic conductivity of $\mathrm{Li}_{7} \mathrm{P}_{3} \mathrm{~S}_{11}$ prepared in $\mathrm{ACN}$ is always higher than in DME. ${ }^{12}$ It can explain as follow: For liquid-phase synthesis in ACN, the amorphous " $\mathrm{Li}_{2} \mathrm{~S} \cdot \mathrm{P}_{2} \mathrm{~S}_{5}$ " phase is dissolved in the solvent. As long as the precursor suspension is well dispersed during drying, " $\mathrm{Li}_{2} \mathrm{~S} \cdot \mathrm{P}_{2} \mathrm{~S}_{5}$ " will homogenously wrap the solvated $\mathrm{Li}_{3} \mathrm{PS}_{4}$ precipitates. The intimate contact between the two phases facilitates 
the following solid-state reaction between them, so that less impurities remain in the resultant $\mathrm{Li}_{7} \mathrm{P}_{3} \mathrm{~S}_{11}$ and consequently high ionic conductivity is achieved. Differently, for the synthesis in DME, both the amorphous " $\mathrm{Li}_{2} \mathrm{~S} \cdot \mathrm{P}_{2} \mathrm{~S}_{5}$ " phase and the solvated $\mathrm{Li}_{3} \mathrm{PS}_{4}$ precipitate. The contact between them is not as intimate as in ACN. Therefore, the following solid-state reaction between the two phase is less thorough, which leads to more residual impurities and poorer ionic conductivity.

Perceiving the different solubility of the amorphous " $\mathrm{Li}_{2} \mathrm{~S} \cdot \mathrm{P}_{2} \mathrm{~S}_{5}$ " phase in different solvent also helps us to better understand the previously reported phenomena observed during solvent-assisted mechano-synthesis of $\mathrm{Li}_{7} \mathrm{P}_{3} \mathrm{~S}_{11}$. It is observed that the SEs synthesized by ACN-assisted ball milling always contain a large amount of thio-LISICON III phase, while those synthesized by DME-assisted ball milling have purer $\mathrm{Li}_{7} \mathrm{P}_{3} \mathrm{~S}_{11}$ phase. ${ }^{19}$ During the solvent-assisted ball milling, the quantity of used solvent is smaller than normal liquid-phase synthesis $\left(4 \mathrm{~g} \mathrm{Li}_{2} \mathrm{~S}-\mathrm{P}_{2} \mathrm{~S}_{5}\right.$ mixture in $12-16$ $\mathrm{ml}$ solvent). The high concentration of " $\mathrm{Li}_{2} \mathrm{~S} \cdot \mathrm{P}_{2} \mathrm{~S}_{5}$ " in $\mathrm{ACN}$ makes the supernatant viscous. The supernatant tends to stick on the milling jars and the mortar \& pestle. Therefore, the precursor is actually in the precipitate-excess region, resulting in a large amount of thio-LISICON III phase in the SEs. When using DME as the solvent, the amorphous " $\mathrm{Li}_{2} \mathrm{~S} \cdot \mathrm{P}_{2} \mathrm{~S}_{5}$ " phase and the solvated $\mathrm{Li}_{3} \mathrm{PS}_{4}$ coprecipitate so the loss of supernatant has little effect on the SEs.

\section{Conclusions}

This work demonstrates that during liquid-phase synthesis of solid electrolyte $\mathrm{Li}_{7} \mathrm{P}_{3} \mathrm{~S}_{11}$ in $\mathrm{ACN}$, the precipitate/supernatant ratio has a notable influence on the phase 
structure, the morphology and consequently the ionic conductivity of the products. In the supernatant-excess region, where the nominal $\mathrm{Li}_{2} \mathrm{~S} \%$ is less than $70.0 \%$, the residual $\mathrm{Li}_{4} \mathrm{P}_{2} \mathrm{~S}_{6}$ tends to form a paste-like morphology which aggregates the $\mathrm{Li}_{7} \mathrm{P}_{3} \mathrm{~S}_{11}$ particles and deteriorates the total ionic conductivity. Therefore, slightly increasing $\mathrm{Li}_{2} \mathrm{~S} \%$ to shift the composition into the precipitate-excess region can inhibit the formation of the paste-like $\mathrm{Li}_{4} \mathrm{P}_{2} \mathrm{~S}_{6}$, and consequently improves the total ionic conductivity by three times.

It is also perceived that the influence of the precipitate/supernatant ratio observed during the synthesis of $\mathrm{Li}_{7} \mathrm{P}_{3} \mathrm{~S}_{11}$ in $\mathrm{ACN}$ is not universally adoptable for other solvents, such as DME. The essential difference is that one of the components in the suspension, the amorphous " $\mathrm{Li}_{2} \mathrm{~S} \cdot \mathrm{P}_{2} \mathrm{~S}_{5}$ " phase, is not always soluble in other solvents. The solubility of " $\mathrm{Li} 2 \mathrm{~S} \cdot \mathrm{P}_{2} \mathrm{~S}_{5}$ " is proposed to be governed by the dielectric properties of the solvents. Structure-property-processing insights will continue to advance the field of solid electrolytes for solid batteries and other electrochemical devices.

\section{Conflicts of interest}

The authors declare no competing financial interests

\section{Acknowledgement}

This work is the financially supported by the National Natural Science Foundation of China

(No. 51702216/61504085), the Natural Science Foundation of Guangdong Province (No. 2017A030313325), the Shenzhen Key Lab Fund (ZDSYS20170228105421966), and the Natural Science Foundation of Shenzhen University (No. 827-000125/827-000089).

\section{References}


1. Fan L, Wei S, Li S, Li Q, Lu Y. Recent Progress of the Solid-State Electrolytes for High-Energy Metal-Based Batteries. Advanced Energy Materials. 2018;8(11):1702657.

2. Liu D, Zhu W, Feng Z, Guerfi A, Vijh A, Zaghib K. Recent progress in sulfide-based solid electrolytes for Li-ion batteries. Materials Science and Engineering: B. 2016;213:169-76.

3. Kamaya N, Homma K, Yamakawa Y, Hirayama M, Kanno R, Yonemura M, Kamiyama T, Kato Y, Hama S, Kawamoto K, Mitsui A. A lithium superionic conductor. Nat Mater. 2011;10(9):682-6.

4. Seino Y, Ota T, Takada K, Hayashi A, Tatsumisago M. A sulphide lithium super ion conductor is superior to liquid ion conductors for use in rechargeable batteries. Energy Environ Sci. 2014;7(2):627-31.

5. Kato Y, Hori S, Saito T, Suzuki K, Hirayama M, Mitsui A, Yonemura M, Iba H, Kanno R. High-power all-solid-state batteries using sulfide superionic conductors. Nature Energy. 2016;1:16030.

6. Yao X, Huang N, Han F, Zhang Q, Wan H, Mwizerwa JP, Wang C, Xu X. High-Performance All-Solid-State Lithium-Sulfur Batteries Enabled by Amorphous Sulfur-Coated Reduced Graphene Oxide Cathodes. Advanced Energy Materials. 2017;7(17):1602923.

7. Xu R-C, Xia X-H, Li S-H, Zhang S-Z, Wang X-L, Tu J-P. All-solid-state lithium-sulfur batteries based on a newly designed $\mathrm{Li}_{7} \mathrm{P}_{2.9} \mathrm{Mn}_{0.1} \mathrm{~S}_{10.7} \mathrm{I}_{0.3}$ superionic conductor. J Mater Chem A. 2017;5(13):6310-7. 
8. Sakuda A, Takeuchi T, Kobayashi H. Electrode morphology in all-solid-state lithium secondary batteries consisting of $\mathrm{LiNi}_{1 / 3} \mathrm{Co}_{1 / 3} \mathrm{Mn}_{1 / 3} \mathrm{O}_{2}$ and $\mathrm{Li}_{2} \mathrm{~S}_{-} \mathrm{P}_{2} \mathrm{~S}_{5}$ solid electrolytes. Solid State Ionics. 2016;285:112-7.

9. Wei J, Kim H, Lee D-C, Hu R, Wu F, Zhao H, Alamgir FM, Yushin G. Influence of annealing on ionic transfer and storage stability of $\mathrm{Li}_{2} \mathrm{~S}-\mathrm{P}_{2} \mathrm{~S}_{5}$ solid electrolyte. J Power Sources. 2015;294:494-500.

10. Hayashi A, Minami K, Mizuno F, Tatsumisago M. Formation of $\mathrm{Li}^{+}$superionic crystals from the $\mathrm{Li}_{2} \mathrm{~S}-\mathrm{P}_{2} \mathrm{~S}_{5}$ melt-quenched glasses. Journal of Materials Science. 2008;43(6):1885-9.

11. Nagao M, Hayashi A, Tatsumisago M. Sulfur-carbon composite electrode for all-solid-state $\mathrm{Li} / \mathrm{S}$ battery with $\mathrm{Li}_{2} \mathrm{~S}-\mathrm{P}_{2} \mathrm{~S}_{5}$ solid electrolyte. Electrochim Acta. 2011;56(17):6055-9.

12. Miura A, Rosero-Navarro NC, Sakuda A, Tadanaga K, Phuc NHH, Matsuda A, Machida N, Hayashi A, Tatsumisago M. Liquid-phase syntheses of sulfide electrolytes for all-solid-state lithium battery. Nature Reviews Chemistry. 2019;3(3):189-98.

13. Liu Z, Fu W, Payzant EA, Yu X, Wu Z, Dudney NJ, Kiggans J, Hong K, Rondinone AJ, Liang C. Anomalous High Ionic Conductivity of Nanoporous $\beta$-Li3PS4. J Am Chem Soc. 2013;135(3):975-8.

14. Rangasamy E, Liu Z, Gobet M, Pilar K, Sahu G, Zhou W, Wu H, Greenbaum S, Liang C. An Iodide-Based $\mathrm{Li}_{7} \mathrm{P}_{2} \mathrm{~S}_{8} \mathrm{I}$ Superionic Conductor. J Am Chem Soc. 2015;137(4):1384-7. 
15. Calpa M, Rosero-Navarro NC, Miura A, Tadanaga K. Instantaneous preparation of high lithium-ion conducting sulfide solid electrolyte $\mathrm{Li}_{7} \mathrm{P}_{3} \mathrm{~S}_{11}$ by a liquid phase process. RSC Advances. 2017;7(73):46499-504.

16. Yao X, Liu D, Wang C, Long P, Peng G, Hu Y-S, Li H, Chen L, Xu X. High-Energy All-Solid-State Lithium Batteries with Ultralong Cycle Life. Nano Lett. 2016;16(11):7148-54

17. Ito S, Nakakita M, Aihara Y, Uehara T, Machida N. A synthesis of crystalline $\mathrm{Li}_{7} \mathrm{P}_{3} \mathrm{~S}_{11}$ solid electrolyte from 1,2-dimethoxyethane solvent. J Power Sources. 2014;271:342-5.

18. Wang Y, Lu D, Bowden M, El Khoury PZ, Han KS, Deng ZD, Xiao J, Zhang J-G, Liu J. Mechanism of Formation of $\mathrm{Li}_{7} \mathrm{P}_{3} \mathrm{~S}_{11}$ Solid Electrolytes through Liquid Phase Synthesis. Chem Mater. 2018;30(3):990-7.

19. Xue B, Fan B, Li B, Chen L, Wang F, Luo Z, Zhang X, Ma H. Solvent-assisted ball milling for synthesizing solid electrolyte $\mathrm{Li}_{7} \mathrm{P}_{3} \mathrm{~S}_{11}$. J Am Ceram Soc. 2019;102:3402-10.

20. Xu RC, Xia XH, Yao ZJ, Wang XL, Gu CD, Tu JP. Preparation of $\mathrm{Li}_{7} \mathrm{P}_{3} \mathrm{~S}_{11}$ glass-ceramic electrolyte by dissolution-evaporation method for all-solid-state lithium ion batteries. Electrochim Acta. 2016;219:235-40.

21. Wang H, Hood ZD, Xia Y, Liang C. Fabrication of ultrathin solid electrolyte membranes of $\beta-\mathrm{Li}_{3} \mathrm{PS}_{4}$ nanoflakes by evaporation-induced self-assembly for all-solid-state batteries. J Mater Chem A. 2016;4(21):8091-6.

22. Phuc NHH, Morikawa K, Mitsuhiro T, Muto H, Matsuda A. Synthesis of plate-like $\mathrm{Li}_{3} \mathrm{PS}_{4}$ solid electrolyte via liquid-phase shaking for all-solid-state lithium batteries. Ionics. 2017;23(8):2061-7. 
23. Seino Y, Nakagawa M, Senga M, Higuchi H, Takada K, Sasaki T. Analysis of the structure and degree of crystallisation of $70 \mathrm{Li}_{2} \mathrm{~S}-30 \mathrm{P}_{2} \mathrm{~S}_{5}$ glass ceramic. J Mater Chem A. 2015;3(6):2756-61.

24. Aoki Y, Ogawa K, Nakagawa T, Hasegawa Y, Sakiyama Y, Kojima T, Tabuchi M. Chemical and structural changes of $70 \mathrm{Li}_{2} \mathrm{~S}-30 \mathrm{P}_{2} \mathrm{~S}_{5}$ solid electrolyte during heat treatment. Solid State Ionics. 2017;310:50-5.

25. Mizuno F, Hayashi A, Tadanaga K, Tatsumisago M. New Lithium-Ion Conducting Crystal Obtained by Crystallization of the $\mathrm{Li}_{2} \mathrm{~S}-\mathrm{P}_{2} \mathrm{~S}_{5}$ Glasses. Electrochem Solid-State Lett. 2005;8(11):A603-A6.

26. Dietrich C, Weber DA, Sedlmaier SJ, Indris S, Culver SP, Walter D, Janek J, Zeier WG. Lithium ion conductivity in $\mathrm{Li}_{2} \mathrm{~S}-\mathrm{P}_{2} \mathrm{~S}_{5}$ glasses - building units and local structure evolution during the crystallization of superionic conductors $\mathrm{Li}_{3} \mathrm{PS}_{4}, \mathrm{Li}_{7} \mathrm{P}_{3} \mathrm{~S}_{11}$ and $\mathrm{Li}_{4} \mathrm{P}_{2} \mathrm{~S}_{7}$. J Mater Chem A. 2017;5(34):18111-9.

27. Kudu ÖU, Famprikis T, Fleutot B, Braida M-D, Le Mercier T, Islam MS, Masquelier C. A review of structural properties and synthesis methods of solid electrolyte materials in the $\mathrm{Li}_{2} \mathrm{~S}-\mathrm{P}_{2} \mathrm{~S}_{5}$ binary system. J Power Sources. 2018;407:31-43.

28. Ward AT. Raman spectroscopy of sulfur, sulfur-selenium, and sulfur-arsenic mixtures. The Journal of Physical Chemistry. 1968;72(12):4133-9.

29. Barsoukov E, Macdonald JR. Impedance Spectroscopy: Theory, Experiment, and Applications, Second Edition Hoboken, NJ, USA: John Wiley \& Sons, Inc.; 2005. 
30. Calpa M, Rosero-Navarro NC, Miura A, Tadanaga K. Preparation of sulfide solid electrolytes in the $\mathrm{Li}_{2} \mathrm{~S}-\mathrm{P}_{2} \mathrm{~S}_{5}$ system by a liquid phase process. Inorganic Chemistry Frontiers. 2018;5(2):501-8.

31. Dietrich C, Sadowski M, Sicolo S, Weber DA, Sedlmaier SJ, Weldert KS, Indris S, Albe K, Janek J, Zeier WG. Local Structural Investigations, Defect Formation, and Ionic Conductivity of the Lithium Ionic Conductor $\mathrm{Li}_{4} \mathrm{P}_{2} \mathrm{~S}_{6}$. Chem Mater. 2016;28(23):8764-73.

32. Hood ZD, Kates C, Kirkham M, Adhikari S, Liang C, Holzwarth NAW. Structural and electrolyte properties of $\mathrm{Li}_{4} \mathrm{P}_{2} \mathrm{~S}_{6}$. Solid State Ionics. 2016;284:61-70.

33. Izutsu K. Electrochemistry in nonaqueous solutions. Weinheim: Wiley-VCH Verlag GmbH \& Co. KGaA; 2002.

34. Rauh RD, Shuker FS, Marston JM, Brummer SB. Formation of lithium polysulfides in aprotic media. J Inorg Nucl Chem. 1977;39(10):1761-6. 